\title{
Sarcoidosis complicated by cirrhosis and hepatopulmonary syndrome
}

\author{
Samir Gupta MD FRCPC ${ }^{1}$, Marie E Faughnan MD FRCPC ${ }^{1}$, Gerald J Prud'homme MD FRCPC ${ }^{2}$, \\ David M Hwang BSc MD PhD FRCPC ${ }^{3}$, David G Munoz MD FRCPC ${ }^{2}$, Peter Kopplin MD FRCPC ${ }^{1}$
}

\begin{abstract}
S Gupta, ME Faughnan, GJ Prud'homme, DM Hwang, DG Munoz, P Kopplin. Sarcoidosis complicated by cirrhosis and hepatopulmonary syndrome. Can Respir J 2008;15(3):124-126.
\end{abstract}

\begin{abstract}
Sarcoidosis is a multisystem disorder commonly affecting the lungs, but also the liver, with cirrhosis and portal hypertension occurring in fewer than $1 \%$ of cases. Although hepatopulmonary syndrome (HPS) is seen in $15 \%$ to $20 \%$ of patients with cirrhosis of varying causes, it has rarely been associated with sarcoidosis. Also, although a brain abscess is not uncommon in patients with discrete pulmonary arteriovenous malformations, it is rarely seen in patients with the much smaller intrapulmonary vascular dilations that characterize HPS. A patient with an unusual series of uncommon sarcoidosis complications, including cirrhosis with HPS, brain abscess and finally Nocardia meningitis, is reported. The possibility of HPS should be considered in sarcoidosis patients with liver involvement, if gasexchange abnormalities are out of proportion to the degree of lung involvement. These patients may also be susceptible to a cerebral abscess by paradoxical embolization, and to opportunistic infections due to cirrhosis.
\end{abstract}

Key Words: Cirrhosis; Liver failure; Pulmonary circulation; Sarcoidosis

Garcoidosis is a multisystem granulomatous disorder that $\checkmark$ most commonly affects the lungs, but can also affect the liver. Cirrhosis and portal hypertension are rare manifestations of sarcoidosis, occurring in fewer than $1 \%$ of cases (1). In turn, hepatopulmonary syndrome (HPS) is defined by a triad of features: liver dysfunction or portal hypertension; intrapulmonary vascular dilations (IPVDs); and abnormal gasexchange, defined by an alveolar-arterial gradient of $20 \mathrm{mmHg}$ or greater. This syndrome is a well-recognized and common complication of liver disease, present in $15 \%$ to $20 \%$ of patients with cirrhosis of varying causes (2). Although HPS has been reported in cases of noncirrhotic portal hypertension with normal synthetic liver function, the most common cause is cirrhosis, athough no specific etiology nor severity of cirrhosis has been found to be correlated with the incidence or severity of HPS (3). The majority of HPS patients (82\%) initially present with features of liver disease; however, a minority $(18 \%)$ present with pulmonary complaints. Thus, a diagnosis of HPS should be kept in mind in the clinical context of unexplained hypoxemia (4). We report a case involving an unusual series of uncommon complications of

\section{Une sarcoïdose compliquée par une cirrhose et un syndrome hépatopulmonaire}

La sarcoïdose est un trouble multisystémique qui touche souvent les poumons, mais également le foie, la cirrhose et l'hypertension portale se produisant dans moins de $1 \%$ des cas. Bien qu'on observe un syndrome hépatopulmonaire (SHP) chez $15 \%$ à $20 \%$ des patients atteints d'une cirrhose aux causes diverses, le SHP s'associe rarement à la sarcoïdose. De plus, même si la présence d'un abcès cérébral est plutôt fréquente chez les patients atteints de malformations artérioveineuses pulmonaires discrètes, on observe rarement ce type d'abcès chez les patients présentant les dilatations vasculaires intrapulmonaires beaucoup plus petites caractéristiques du SHP. Est présenté le cas d'un patient atteint d'une série inhabituelle de complications peu courantes de la sarcoïdose, y compris une cirrhose accompagnée d'un SHP, un abcès cérébral et, enfin, une méningite à Nocardia. Il faut envisager la possibilité d'un SHP chez les patients souffrant d'une sarcoïdose avec atteinte du foie, lorsque les anomalies des échanges gazeux sont sans proportion avec l'importance de l'atteinte pulmonaire. Ces patients peuvent également être vulnérables à un abcès cérébral par embolisation paradoxale et aux infections opportunistes causées par la cirrhose.

sarcoidosis, including cirrhosis with resulting HPS, brain abscess and finally, Nocardia meningitis.

\section{CASE PRESENTATION}

A lifetime nonsmoking Caucasian woman had initially presented in 1983, at 58 years of age, with iritis, hepatosplenomegaly and hypercalcemia, along with diffuse interstitial markings on chest x-ray. An open lung biopsy confirmed sarcoidosis, and she was treated with prednisone for two years, with disease remission. The patient remained well until 1990, when she developed an unexplained frontal lobe brain abscess after a dental procedure. She was successfully treated with intravenous antibiotics.

Between 1991 and 1995, the patient complained of gradually progressive exertional dyspnea. By 1995, she had cyanosis, digital clubbing and numerous spider nevi. Her chest x-ray was normal. Pulmonary function tests revealed normal spirometry and lung volumes, with a diffusion capacity of $43 \%$ predicted and partial pressure of $\mathrm{O}_{2}$ of $47 \mathrm{mmHg}$ on room air. An ultrasound showed hepatosplenomegaly with varices at the porta hepatis. She had no history of alcohol consumption, and all

${ }^{1}$ Department of Medicine, Division of Respirology; ${ }^{2}$ Department of Laboratory Medicine and Pathobiology, St Michael's Hospital; ${ }^{3}$ Toronto General Hospital, University of Toronto, Toronto, Ontario

Correspondence: Dr Samir Gupta, St Michael's Hospital, 6-045 Bond Wing, 30 Bond Street, Toronto, Ontario M5B 1W8.

Telephone 416-864-6026, fax 416-864-5649, e-mail guptas@smh.toronto.on.ca 


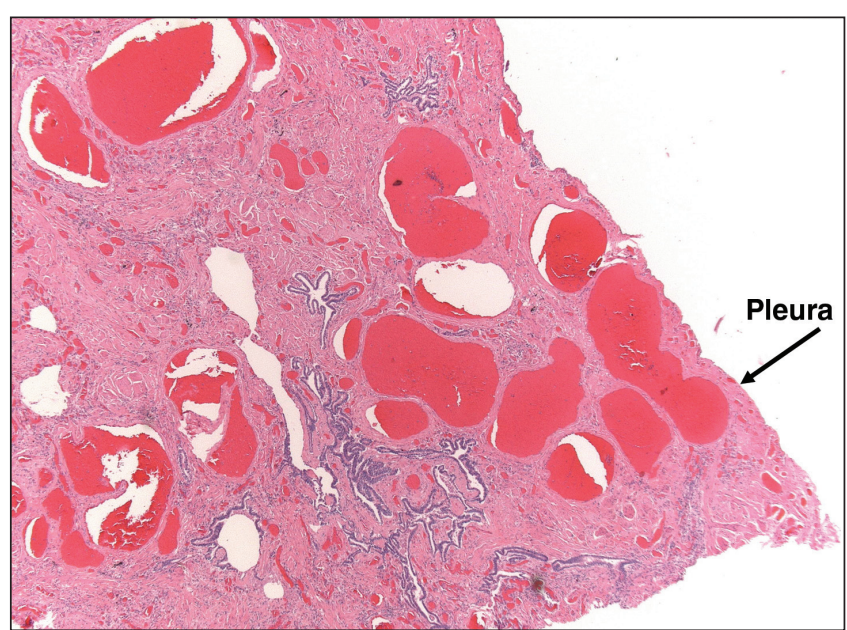

Figure 1) Photomicrograph of a lung section showing enlarged vessels adjacent to the pleura ('pleural spiders') (hematoxylin and eosin stain, original magnification $\times 25$ ). Arrow

liver serologies were negative. A liver biopsy then confirmed typical sarcoid-type granulomatous hepatitis, with cirrhosis. Transesophageal bubble echocardiogram revealed delayed appearance of bubbles in the left atrium through the pulmonary veins with no intracardiac shunt, confirming the presence of IPVDs. A presumptive diagnosis of HPS secondary to sarcoid cirrhosis was made. A subsequent pulmonary angiogram revealed no discrete macroscopic arteriovenous malformations (AVMs) and normal pulmonary artery pressures. Prednisone therapy was reinstituted in January 1996, but stopped definitively in September 1996 because of a lack of improvement.

By early 2004, baseline oxygen saturations were in the $65 \%$ to $75 \%$ range, despite supplemental home oxygen therapy of $5 \mathrm{~L} / \mathrm{min}$ to $8 \mathrm{~L} / \mathrm{min}$ by nasal prongs (the patient had refused a mask). In August 2004, at 79 years of age, she presented with a three-day history of worsening dyspnea, generalized weakness and new-onset confusion. She was hemodynamically stable and afebrile, and laboratory investigations revealed an elevated white blood cell count of $12.2 \times 10^{9} / \mathrm{L}$ and an elevated troponin concentration of $1.68 \mu \mathrm{g} / \mathrm{L}$. An electrocardiogram showed lateral ST segment depressions. Her chest $\mathrm{x}$-ray was unremarkable. She was treated for a non-ST elevation myocardial infarction, believed to be secondary to supply-demand type ischemia due to low oxygen saturation. Unfortunately, she suffered a cardiac arrest and passed away two days after admission.

An autopsy confirmed liver cirrhosis and diffuse interstitial fibrosis of the lungs consistent with 'burnt-out' sarcoidosis. In addition, pulmonary sections showed pleural-based spider angiomas (Figure 1), as well as widespread enlargement of the vascular spaces (Figure 2), which were more prominent in the lower lobes, characteristic of the IPVDs seen in HPS. Brain sections revealed focal intracerebral hemorrhage, local cerebral vasculitis and unexpected bacterial meningitis (characterized by discrete colonies of filamentous branching organisms most consistent with Nocardia species).

\section{DISCUSSION}

HPS is an extremely rare complication of sarcoidosis, with only one previous report in the literature (5). Furthermore, our patient developed an unexplained brain abscess following a

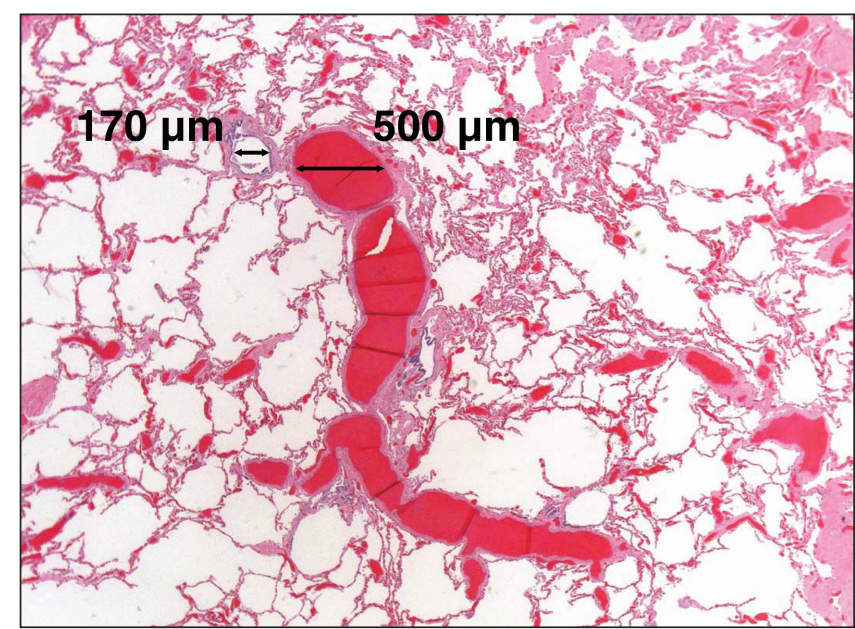

Figure 2) Photomicrograph of a lung section showing a bronchiole with enlarged accompanying pulmonary vessels (hematoxylin and eosin stain, original magnification $\times 16$ )

dental procedure, five years before the diagnosis of HPS. Given that IPVDs develop progressively, we hypothesized that the present patient had IPVDs long before the onset of symptomatic hypoxemia, and that her brain abscess might have resulted from right-to-left bacterial transit through lung IPVDs at the time of her dental procedure. This is supported by previous cross-sectional studies demonstrating the presence of IPVDs without hypoxemia among cirrhotic subjects (6). It is of note that although brain abscess is a recognized complication of pulmonary AVMs through this paradoxical embolization mechanism, it rarely occurs in HPS, presumably due to the relatively smaller calibre and decreased flow through IPVDs. However, two previously published case reports of a brain abscess in patients with HPS, have suggested that IPVDs may occasionally behave like 'true' pulmonary AVMs with respect to loss of the lung's 'filter' function $(7,8)$.

In terms of the underlying cause of the IPVDs that characterize HPS, several pathophysiological models have been proposed (2). It has been suggested that IPVDs may result from increased production or impaired hepatic clearance of constitutively produced vasodilators, or alternatively, from decreased production of or lack of pulmonary vascular sensitivity to a vasoconstrictor normally emanating from a healthy liver. However, regardless of the upstream triggering pathway, it has become evident in rat models of this disease that locally released nitric oxide is an important end-mediator of vascular dilation at the level of the pulmonary microvasculature (9).

Finally, in our patient, autopsy revealed the unexpected complication of Nocardia meningitis with resulting focal vasculitis and cerebral hemorrhage. The patient had none of the 'usual' causes of an immunocompromised state, such as HIV or chronic steroid use, and we suspect that cirrhosis was the predisposing factor.

\section{CONCLUSION}

Cirrhosis from sarcoidosis may cause HPS, which must be kept in mind, especially if gas-exchange abnormalities are out of proportion to the degree of lung involvement by sarcoidosis. Also, patients with HPS may develop cerebral abscess as a result of right-to-left shunting of bacteria through IPVDs; this may occur even before the onset of symptomatic hypoxemia. Finally, 
patients with cirrhosis may be functionally immunocompromised, and the possibility of opportunistic infections should be entertained.

ACKNOWLEDGEMENTS: We would like to thank Dr Victor Hoffstein for his insightful comments about this report.

\section{DISCLOSURE OF PERSONAL OR FINANCIAL SUPPORT:}

Dr Samir Gupta is supported by the University of Toronto Clinician Scientist Training Program and the Canadian Lung Association. Dr Marie E Faughnan is supported by St Michael's Hospital Research Institute and the Nelson Arthur Hyland Foundation.

\section{REFERENCES}

1. Blich M, Edoute Y. Clinical manifestations of sarcoid liver disease. J Gastroenterol Hepatol 2004;19:732-7.

2. Rodríguez-Roisin R, Krowka MJ, Hervé P, Fallon MB. Pulmonaryhepatic vascular disorders. Eur Respir J 2004;24:861-80.
3. Castro M, Krowka MJ. Hepatopulmonary syndrome. A pulmonary vascular complication of liver disease. Clin Chest Med 1996; 17:35-48

4. Krowka MJ, Dickson ER, Cortese DA. Hepatopulmonary syndrome. Clinical observations and lack of therapeutic response to somatostatin analogue. Chest 1993;104:515-21.

5. Ganguli SN, Steinhardt MI, Kundu S. Hepatopulmonary syndrome associated with sarcoidosis of the liver: Case report. Can Assoc Radiol J 1998;49:411-4.

6. Lima BL, França AV, Pazin-Filho A, et al. Frequency, clinical characteristics, and respiratory parameters of hepatopulmonary syndrome. Mayo Clin Proc 2004;79:42-8.

7. Molleston JP, Kaufman BA, Cohen A, et al. Brain abscess in hepatopulmonary syndrome. J Pediatr Gastroenterol Nutr 1999;29:225-6.

8. Añel RM, Sheagren JN. Novel presentation and approach to management of hepatopulmonary syndrome with use of antimicrobial agents. Clin Infect Dis 2001;32:E131-6.

9. Nunes H, Lebrec D, Mazmanian M, et al. Role of nitric oxide in hepatopulmonary syndrome in cirrhotic rats. Am J Respir Crit Care Med 2001;164:879-85. 


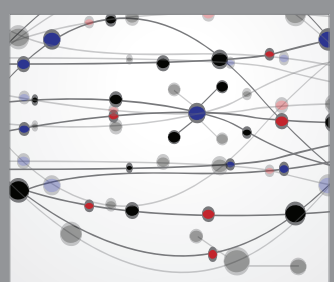

The Scientific World Journal
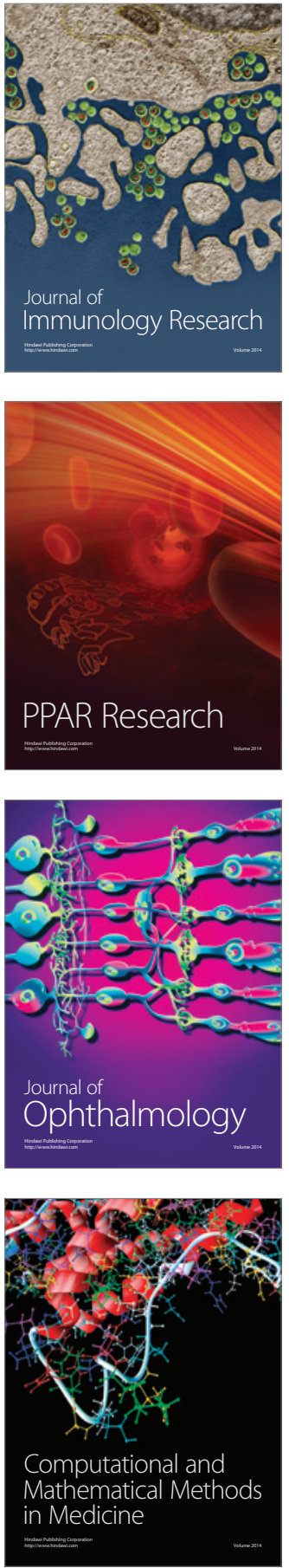

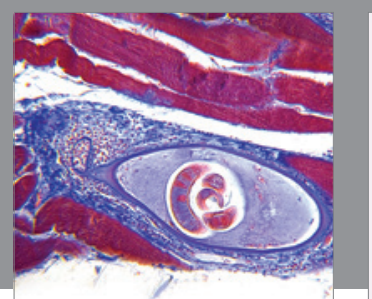

Gastroenterology Research and Practice

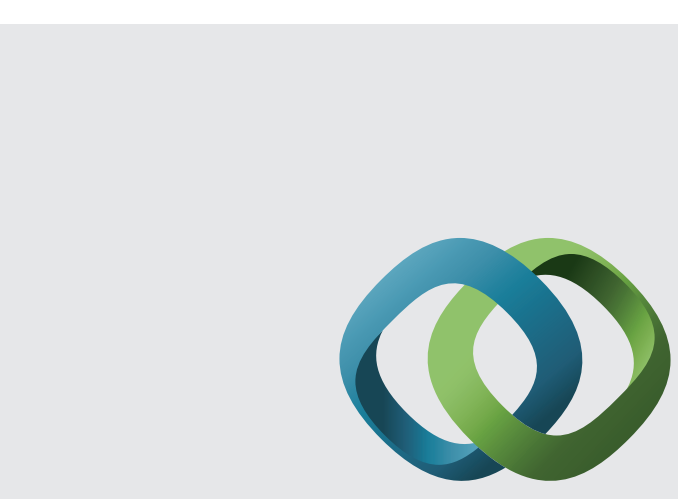

\section{Hindawi}

Submit your manuscripts at

http://www.hindawi.com
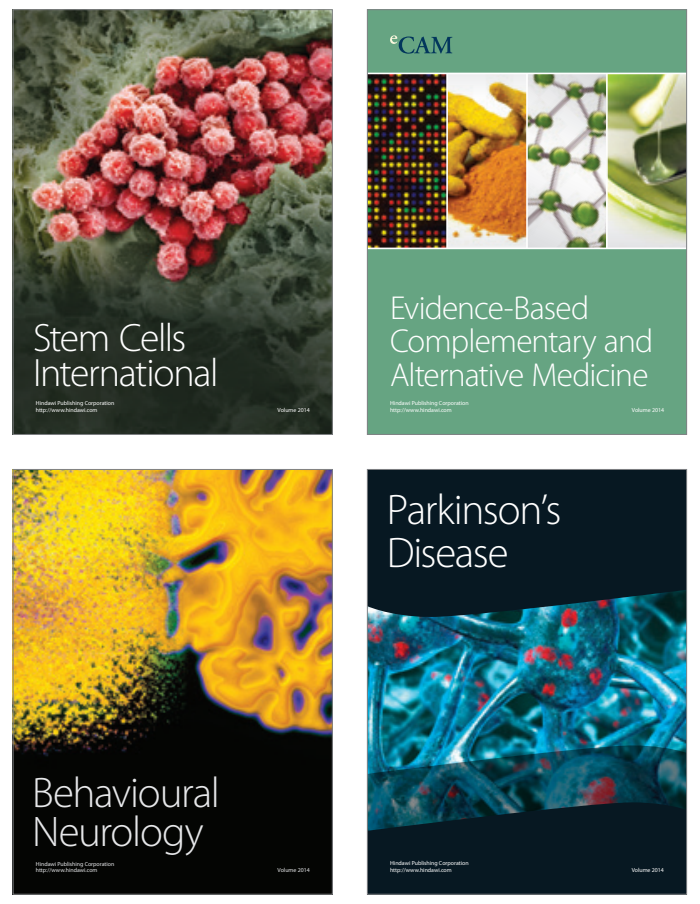
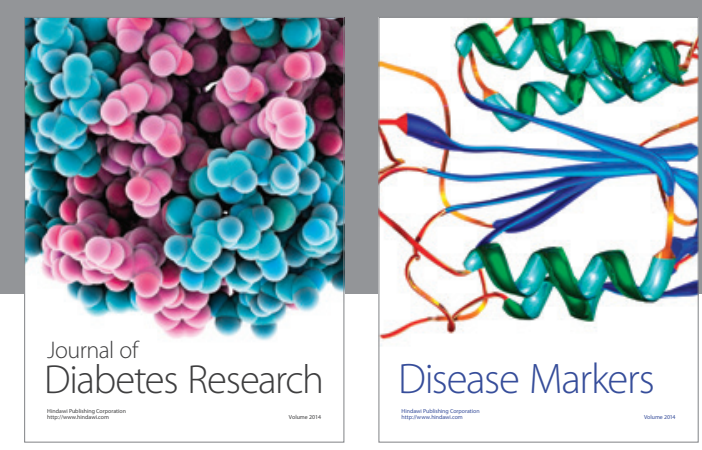

Disease Markers
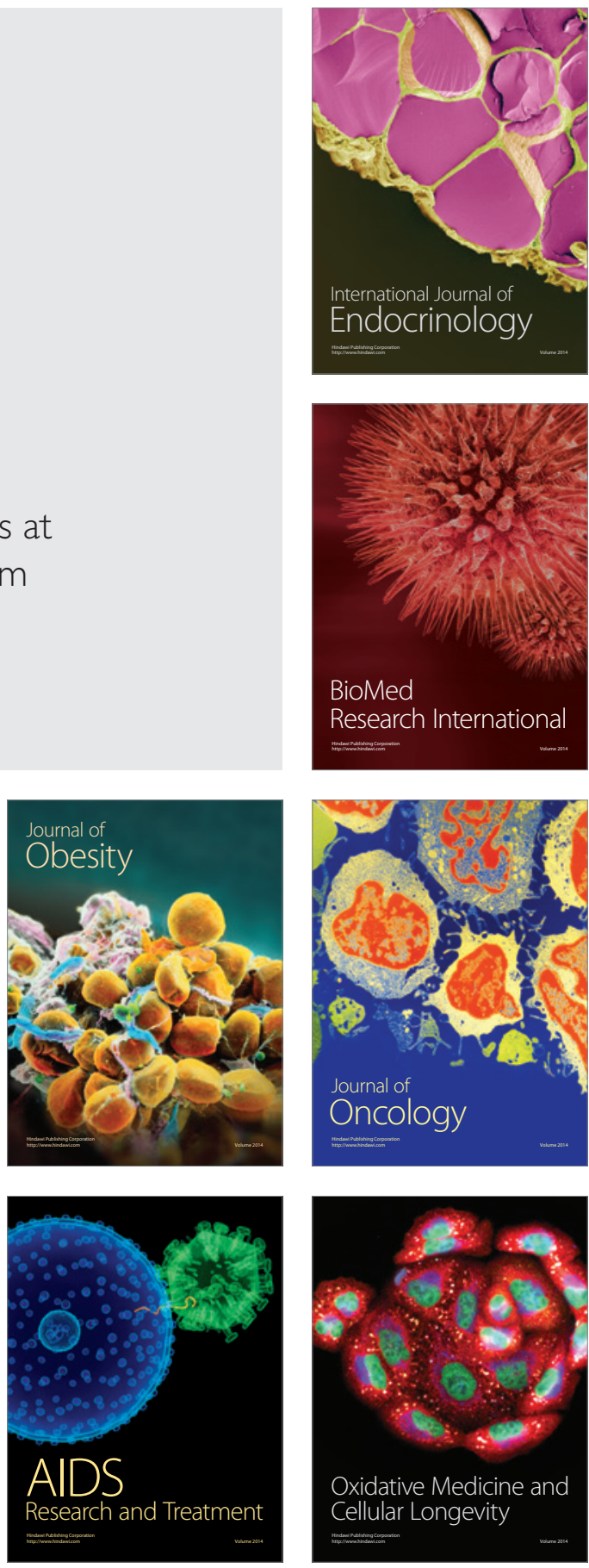